\title{
Rail transport in supply chains
}

\author{
JEL: L92 DOI: 10.24136/atest.2018.513 \\ Data zgłoszenia: 19.11.2018 Data akceptacji: 15.12.2018
}

The paper discusses the problem of competitiveness between the rail and road transport with reference to the EU policy for sustainable development of the transport branch. The paper presents the idea of complexity of services which facilitates the development of logistic networks. The authors formulate preliminary assumptions recommended for designing and construction of multimodal hubs. Further, they describe examples of European and Polish businesses which, thanks to the consolidation of services, widened their offer of logistic capabilities. The authors highlight the need for action aiming at the reversal of the unfavorable trend and increasing the cargo flow by rail, and not road. Finally, they discuss the necessity to reform the current freight transport by rail through the construction of comprehensive supply chains.

Key words: multimodal hub, supply chain, logistic network, spot infrastructure, complexity of services.

\section{Introduction}

Road transport prevails in the European Union. Subsequently, this branch of economy is strongly dependent on crude oil and its derivatives. However, crude oil comes in $80 \%$ from resources outside Europe and it cost about 230 bn euro to import it in 2012. The consumption of such a huge amount of fuel causes emission of destructive exhaust fumes, inclusive of $\mathrm{Co}$, into the atmosphere. Hence, the European Commission is looking for new solutions to reduce the harmful impact of transport on natural environment. Lobby representatives for road transport very often raise the argument that cargo transportation by rail also requires the production of electric energy. This is correct, however, it is undoubtedly more feasible to intercept fumes from one source, such as powerhouse chimney, than from a few thousand of mobile sources of fumes. It is also easier to monitor the emission of harmful fumes. Much lower consumption of energy, the occupation of much less area to carry a statistical ton of cargo, or the elimination of road congestion are among many significant arguments supporting the necessity to increase the role of rail on the freight transport market. It must be noted that the functioning of the rail system is closely dependent on the line and spot infrastructure. Henceforth, while designing future investments and during the construction of multimodal hubs, particular attention must be paid to the necessity to create proper network of rail infrastructure services. The market which witnesses high intra-branch competitiveness (among rail transport operators) as well as external competitiveness caused by road transport, which is additionally favored by the state, the playing field is uneven and has more than one level. The aim of the paper is to present rail transport in the context of supply chains creation.

\section{ROLE OF RAIL TRANSPORT IN SUPPLY CHAINS}

Over the last few years logistics has been changing fast and customer expectations as for the form of offered services have changed as well. It is the comprehensiveness of services in supply chains creation that matters when choosing the service provider. It is particularly important in the context of identification of the essential areas of supply chain. Undoubtedly, transport is one of these essential areas. See chart 1.

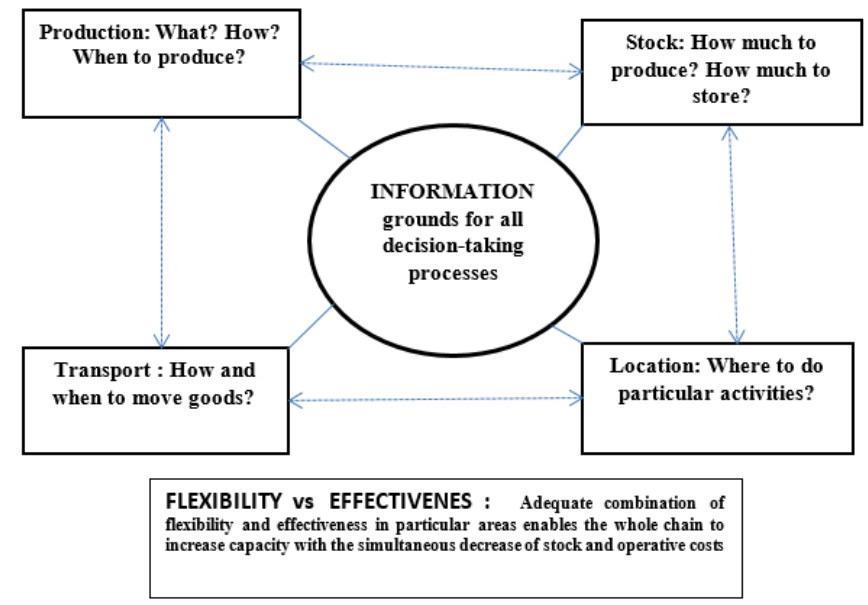

Chart 1. Main areas of supply chain

Source: M. Antonowicz: People, as the power engine of supply chains, Management and Business Administration. Central Europe" Vol. 23, No. 1(124): Copyright by Koźmiński University Warsaw 2014 p.108

The choice of rail transport as the means of moving goods depends on the flexibility and effectiveness of this transportation form. Increasing the participation of rail transport in supply chains involves the necessity to make an array of investments such as building, rebuilding and modernization of the line and spot infrastructure. Currently functioning rail network features all the more shortages of rail spot infrastructure of multimodal character. Rail investments at rail lines should involve the development of new freight re-loading infrastructure, adapted to the modern market needs, which will allow for consistent railway network, still open for cargo transport development. It should enable harmonious functioning of all transport branches and therefore it should be of intermodal character. Within the common European market there are a lot of operators, from different sectors, looking for a possibility to improve their competitive stand. Such tendencies are also seen in TSL sector of transport shipment - logistics. More and more often, the cargo rail transport practises consolidation, integration and creation of logistic network which facilitates the use of partners' resources, joint realization of ventures as well as benefiting from the synergy effect. When put together for comparison, the two main means of land transport road and rail - reveal some commonly shared as well as different features. We can say, with a certain dose of confidence, that due to higher functional flexibility and mobility as well as more complex line and spot infrastructure the road transport, and not the rail transport, is chosen by logistic operators in the process of developing a supply chain. Most often it satisfies the expectations as regards the price and quality. With some degree of simplification we can assume that the supply chain is a system of subjects and dependencies occurring around the two flows, i.e. supply and demand. While the demand flow (for goods and services) is created exclusively by the information passing from the customer to the businesses or individ- 
uals who can meet their needs, the supply flow includes property flow such as natural resources, materials and ready- made goods. These processes are undoubtedly associated with cash flow and information flow. See chart 2.

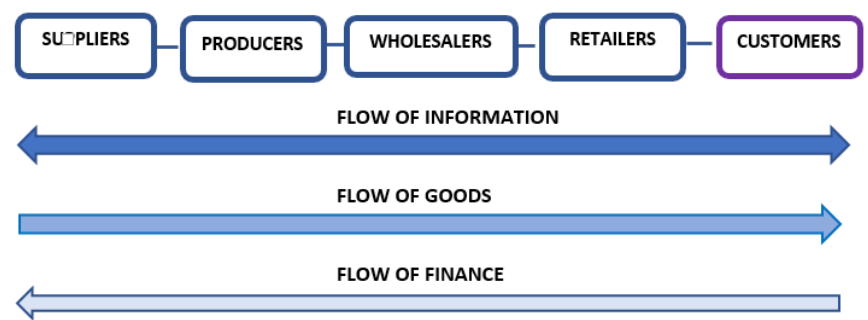

Chart. 2 Exemplary relations and flow in a supply chain

Source: J. J. Coyle, E. J. Bardi, Langley C. John Jr.,Logistic management, PWE Warsaw 2010 p. 30.

In a properly organized supply chain it is crucial for all types of flow to be reliable, meet the deadlines and volume requirements as well as ensure the completeness of the service and delivery. From the customer's point of view, the price also matters. Supply chains' usual objective is to adapt the particular type of goods, services, information or financial resources to its subsequent phases so that the final outcome should meet the client's expectation. Along the way, we get the type of service which is often the transportation service $^{1}$. Therefore, it can be said that transportation (which takes a variety of forms and character, from intra-business through national to intercontinental) plays an important role in a supply chain. Transport significantly affects the effectiveness of production, trade or service-providing businesses so its efficiency is of vital importance to the economic functioning of regions or countries. Transport constitutes the critical element of logistic system because it ensures the transformation of goods in space and time. Consequently, transport requires careful planning, organization and onthe-go monitoring both in its internal and external dimensions ${ }^{2}$. Thus, its efficiency, reliability and flexibility in adaptation to the market requirements greatly conditions the accuracy in the functioning of the whole supply chain. Currently, the development of supply chains is influenced by new means of communication as well as increased effectiveness of logistic processes. High competitiveness on the market of goods and services results in distribution pressure to shorten the delivery time. Contemporary market players expect delivery of goods at precisely determined time and to the specified place. Such market needs precondition the necessity to not only develop singular supply chains but, above all, effective and flexible as well as fast-operating logistic networks which would function both locally and globally. This idea was perfectly presented by Gattorna ${ }^{3}$ on the example of South African railway (see chart 3). South African cargo railway operates within the framework of cooperating supply chains in a particular field of industry. Electronic markets are created which fit the needs of suppliers and buyers. Then, $4 \mathrm{PL}-$ virtual logistics integrator is employed to coordinate the performance of tasks realized in reality by other operators, such as 3PL and transport businesses dealing only with carriage.

\section{Complex supply chains - element of developmental strategy of a business}

One can say that logistic network is a group of operators or modal spots (in the case of railway: logistic support infrastructure) on a given area which cooperate in managing an array of supply

${ }_{1}^{1}$ Approximately, $70-80 \%$ of logistic processes are transportation processes

${ }^{2} \mathrm{Abt}$ S. Logistics in theory and practice, AE, Poznan 2001

3 J. Gattorna, Dynamic supply chains, Eurlogistics, Suchy Las 2013 p. 293 chains in order to achieve high efficiency and effectiveness of the flow of goods in accordance with the clients' requirements ${ }^{4}$. In the case of rail transport these businesses perform the essential service, i.e., transportation and associated services, such as reloading, warehousing, sorting or packaging. Accessibility to transport infrastructure, its density and technical condition have always had and will continually have significant influence on the development of cargo transport market. As regards the competition for the client, the vital factors here are the quality and wholeness of services provided as well as the freight rate quoted. In the situations when the freight rate due to high competition is lowered to the bottom line, the quality and complexity of services become the more decisive element of competition. Consequently, leading European rail transport businesses are creating clusters or consortia in order to be able to offer comprehensive supply chains. Another example is PKP CARGO S.A. which formed a group of specialized operators who provide such services as transportation, shipment, customs clearance, reloading, storage, packaging, big-bagging, servicing railroad siding, etc. However, the network is still insufficient as regards the range and scope of logistic services offered. New quality of customer service has contributed to the increased customers' interest in the services offered by the group. Another example are the German railways and their alliance with the Dutch and Danish railways as well as the development of the network around Europe. With significant support from the state, the takeover of Stinnes AG by DB CARGO has opened a new direction in rail transport on the European transport market ${ }^{5}$. In the course of expansion on the markets of new European Union member states, DB Schenker Rail, followed by DB Schenker Rail Poland bought shares in the Polish transport operators and so expanded its activity into Poland. In January 2011 District Court in Katowice-Wschód in Katowice registered the merger of businesses of DB Schenker Rail Poland Group consisting in the takeover by DB Schenker Rail Poland S.A. of the following businesses: DB Schenker Rail Rybnik S.A., DbB Schenker Rail Zabrze S.A., Trawipol Sp. Z o.o., NZTK Sp. z 0.0., Energoport Sp. z o.0. and PUT Trans - PAK Sp. z 0.0. German railways hold, within their structures, the operators engaged in road transport, serving small flows of cargo and offering carriage of the so called last mile and managing logistic centers. The process of developing a competitive transport operator presented here, now called DB CARGO, is one of many which led to the divisions on the market that now holds 67 carrier operators.

In the examples presented above, as a result of businesses integration, a chain of links has been created and the packet of logistic offer has grown. Place, size and organizational complexity of the leading European rail transport operators together with the new operating segments have given rise to logistic networks of significant scale in the rail transport. However, the development of an organization functioning within a network requires proper adjustment of spot infrastructure (ultra-modern reloading hubs) and line infrastructure as well as furnishing it with the tools of IT support. Such network can undertake effective competition with road transport to win the customer. Rail transport should catch up on the wide range of logistic offer present on the market. Such is the requirement of the contemporary TSL market. Up-to-date operations of the rail transport businesses have been basically focused on the intrabranch competition and survival. Organizational and capital changes have been made within the existing potential without making

4 J. Gattorna, Dynamic supply chains, Eurlogistics, Such Las 2013 p. 293

5 See M. Antonowicz, H. Zielasiewicz, Role of Rail Cargo Transport in development of logistic network. Materials from Poznan conference 19-24 May 2004. 
investments in the development of cutting-edge logistic infrastructure enabling operations in new areas.

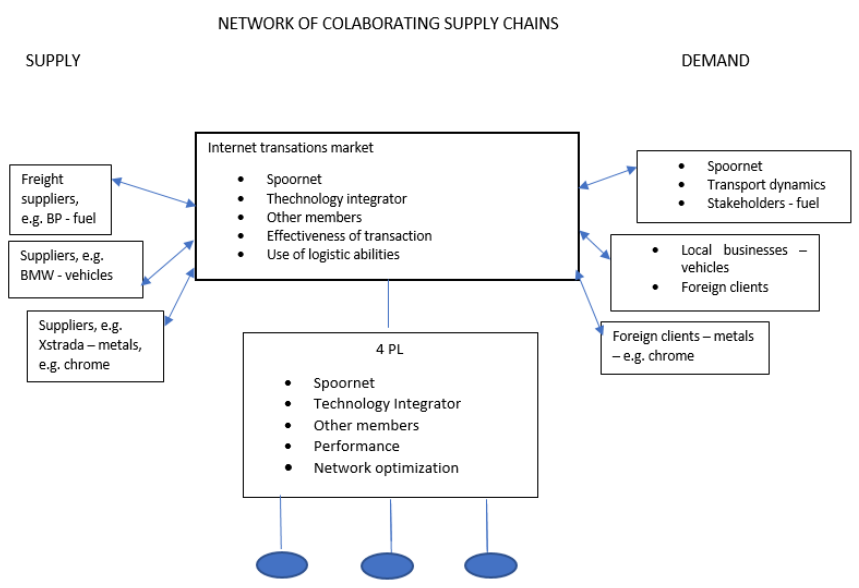

Chart 3. Logistically transforming railway

Source: M. Antonowicz, Business Models of Rail Freight Service Operators and their Value for Clients Creation, Logistics and Transport No 2/2016 pp. 57-65 following J. Gattorna, Dynamic supply chains, Eurlogistics, Such Las 2013, p. 293.

Another issue which is important as regards the competition between road and rail transport is the cost of access to the transport infrastructure as well as the contribution of the so called external costs to the overall cost of particular branches of transport. Road transport is highly privileged here; despite its most harmful influence on the environment, it bears hardly any financial burden because of that. By this, a simple principle demanded to be observed elsewhere in life, namely that the wrongdoer should compensate for the harm done, remains neglected. Unfortunately, it is the whole society that pays for the so called external costs arising from the functioning of the road transport: environmental pollution caused by exhaust fumes, generated noise, traffic congestion and road accidents. The most disturbing is the fact that the road transport contributes to the critical and irreversible changes in our environment. Only a few per cent of the local roads have been covered by toll. Such shape of transport policy may be in certain conditions socially justified (development of motorization, new job places, influence of transportation service price on the price of goods and other services). However, in the long run, such policy contributes to the undermining of the principle of sustainable development of particular branches of transport. It must be noted, though that contemporary economy could not properly function without the road transport and its inherent features such as mobility and flexibility. Nonetheless, the participation of the road transport should be limited wherever it can be substituted by more ecological forms of transport. Further dynamic increase in the flow of goods will lead to the increased demand for complex and high-tech solutions for transport. New market conditions will also give rise to considerably higher clients' expectations towards transport-shipment-logistic operators (TSL). In Poland, despite relatively geographically proper land structure of the transport network, the current system has specific characteristics of high exploitation and development cost and low flexibility for the changes in demand. The main objective set for Poland in the future years is to achieve well-balanced transport system in technical, economic and environmental spheres, i.e. uniform spread of transportation tasks upon particular branches of transport. Another challenge to face will be further liberalization of the rail market of transport services and in particular, the passenger transportation as well as the modernization of the line and spot infrastructure by removing the so called "bottlenecks" in neighboring areas with Western and Eastern Europe. In other words - heading for full inter-operativeness in the rail transport. The latter poses a problem for the old member states of the European Union where more and more congestion occurs in some regions and on some roads. This phenomenon is associated with the ongoing isolation of the peripheral regions which in turn is unfavorable from the point of view of territorial cohesion of EU. The occurrence of bottlenecks and the lack of good infrastructure connections disable the access to new markets and limit the potential economic growth and employment. This subsequently adversely affects trans-European transport network which also witnesses more and more congestion: about $7500 \mathrm{~km}$ of roads which constitute $10 \%$ of the network is congested on the daily basis. European Union is constantly on the lookout for new solutions which should allow for significant economic growth together with the assisting effectiveness of the transport system to ensure full benefits on the internal market. An array of documents have been prepared to present the directions for changes as regards equal role of all the branches of transport. These solutions aim at gradual decrease of the role of the road transport and promotion of ecological means of transport inclusive of rail transport. Similar policy should be implemented in our country as well where the existing transport system features shortages of supply in certain areas and low flexibility towards changing demand. Regrettably, this comment also refers to the rail transport. Currently, the road transport is more competitive than the rail transport. The reasons for this are as follows:

- Lack of effective state policy to promote ecological means of transport such as rail, maritime, inland waterways transport. The situation is gradually changing in favour of the rail transport;

- Contrary to the road transport, rail transport operators bear all the costs for access to the infrastructure;

- Despite remarkable investments, poor quality of line infrastructure can still be seen and the modernization works cause a lot of inconvenience;

- Lack of sufficient number of modern container hubs and logistic centres which would facilitate the development of intermodal transport and provision of door-to-door services;

- Unequal distribution of the network of intermodal hubs;

- Unequal distribution of financial resources to maintain the transport land infrastructure. In Poland for a long time $83 \%$ of the allocated budget was dedicated to roads while only $17 \%$ of the budget covered the needs of the rail transport. European Union recommends the proportion of $40 \%$ - rail and $60 \%$ roads;

- Lack of sufficient financial means to modernize and buy specialist rolling stock, such as for intermodal transportation;

- No financial support for the development of the rail service infrastructure to ensure the development of the so called singlewagon transport.

For this reason, there is an urgent need to undertake proper action to reverse the negative trend because the European Union policy is heading towards the development of the intermodal transport and other transportation technologies in accordance with the principle "from road to sea" and the adoption of the adequate strategy for supply chains with the participation of the rail transport. For a few years now we have heard the slogans for sustainable development of particular branches of transport. It is high time the announcements were turned into action. Example approach is offered by Ciesielski and Długosz ${ }^{6}$ where they claim that the supply chain strategy must be an element of corporate strategy. Relations between the corporate strategy and the supply chain strategy

${ }^{6}$ M. Ciesielski, J. Długosz, Supply chains strategies, PWE Warsaw 2007 p. 33 
are understood as the strategy of the whole company and, at the same time, as the strategy of functional operations through the conversion of the business strategy into the strategy of both operations and supply chain ${ }^{7}$. At the same time, the simplest strategies of the supply chain are positioning related to the definition of the key resources, or adjustment of all the elements of the supply chain to a particular position. Adjustment of the supply chain to the demand and the choice of the adequate strategy are the key business decisions. Strategy, understood as such, is nothing else but a set of key choices in time and space ${ }^{8}$.

\section{Conclusions}

Rail transport businesses in Europe need new incentives as well as new operation areas within logistic and management methods. Recently introduced law regulations have set the new direction for action, particularly for the rail service infrastructure. It is becoming necessary to adapt logistic methods and implement them into practical operations on the rail transport market. One of the conditions determining the development of cargo rail transport is the construction of the network of conventional and intermodal hubs as well as modern loading spots managed by the national operator. Poland, in its liberal approach in the rail cargo transport, has considerably overtook the former 15 member states due to liberal approach to the sector entrance barriers. Whether such approach is right, considering the more conservative attitude of countries such as Germany or France - time will tell. In our country this results in price competitiveness which does not always ensure expected quality and the complexity of the service provided. Fierce price competition also contributes to the exploitation, by some private operators, of highly used and worn out rolling stock which in turn affects the quality and safety of carriage and the use of infrastructure. With meagre support for the rail carrier in which the Polish state holds shares, in competition with German and French state rail carriers (earlier subsidies for the German and French railways) there is no level playing field for competition. It must be remembered that rail transport is also a huge market for the production industry and its needs. Practice shows that in western countries it matters where the carriers purchase equipment and other means. Despite their declaration for openness and the enactment of relevant regulations, west European countries have been visibly protecting their market.

\section{References}

1. Antonowicz M., People as the power engine for supply chains, Management and Business Administration. Central Europe" Vol. 23, No. 1(124): Copyright by Koźmiński University Warsaw 2014.
Antonowicz A., Zielaśkiewicz H., Role of Rail Cargo Transport in creation of Logistics network. Conference papers Poznań 1924 May 2004.

2. Antonowicz M., Business Models of Rail Freight Service Operators and Their Value for Clients Creation, Logistics and Transport No. 2/2016.

3. Blaik P., Concept of integrated management, PWE Warsaw 2017.

4. Bozarth C., Handfield R., Introduction to operations and supply chains management, Hellion Gliwice 2007.

5. Ciesielski M., Długosz J., Supply chains strategies, PWE Warsaw 2007.

6. Coyle J.J., Bardi E.J., Langley C. John Jr., Logistics Management, PWE Warsaw 2010.

7. Gattorna J.,,Dynamic supply chains, Eurlogistics, Suchy Las 2013.

8. Obłoj K., Company strategy practice, Poltext 2017.

\section{Rail transport in supply chains}

The paper discusses the problem of competitiveness between the rail and road transport with reference to the EU policy for sustainable development of the transport branch. The paper presents the idea of complexity of services which facilitates the development of logistic networks. The authors formulate preliminary assumptions recommended for designing and construction of multimodal hubs. Further, they describe examples of Europe-an and Polish businesses which, thanks to the consolidation of services, widened their offer of logistic capabilities. The authors highlight the need for action aiming at the reversal of the unfavorable trend and increasing the cargo flow by rail, and not road. Finally, they discuss the necessity to reform the current freight transport by rail through the construction of comprehensive sup-ply chains.

Keywords: multimodal hub, supply chain, logistic network, spot infrastructure, complexity of services.

Autorzy:

dr Mirosław Antonowicz - - Akademia Leona Koźmińskiego, maaw@kozminski.edu.pl

mgr inż. Henryk Zielaskiewicz - Polskie Towarzystwo Logistyczne, henryk.zielaskiewicz@pkp.pl 